\title{
Necrosis de pies y manos en el shock séptico por Klebsiella pneumoniae
}

\author{
Necrosis of the feet and hands in septic shock due to Klebsiella pneumoniae
}

\section{CASO CLÍNICO}

En los cuadros de sepsis grave y shock séptico se producen una serie de mecanismos inflamatorios y vasculopatía que da lugar a manifestaciones cutáneas. Los microorganismos más implicados en estas lesiones incluyen a Neisseria meningitidis y Neisseria gonorrhoeae. Sin embargo, no son cuadros exclusivos de estos microorganismos, sino que también están descritos por otras bacterias como Klebsiella pneumoniae'.

Presentamos el caso de una mujer de 74 años con antecedentes de hipertensión arterial y miocardiopatía hipertensiva con FEVI preservada, enfermedad renal crónica estadio 3 e hipotiroidismo que acudió por síndrome miccional y fiebre de 5 días de evolución. A la exploración física, la paciente presentaba una presión arterial de 99/62 mmHg, FC de 114 lpm, fiebre de $38^{\circ} \mathrm{C}$, auscultación cardiaca normal, crepitantes bibasales, mínimo dolor a la palpación profunda del abdomen de manera difusa sin datos de peritonismo y sin edema en piernas.

Analíticamente destacaba leucocitosis con neutrofilia y ligera plaquetopenia, actividad TP 31\%, INR 2,41 y resto de los parámetros de coagulación normal, creatinina 4,47 mg/dl, PCR $185 \mathrm{mg} / \mathrm{dl}$ y lactato $6 \mathrm{mmol} / \mathrm{L}$. En TC abdominal se evidenció uropatía obstructiva secundaria a litiasis ureteral, por lo que se colocó catéter doble J. Con el diagnóstico de shock séptico de origen urinario, se inició piperacilina-tazobactam. En hemocultivos y urocultivo retirados se aisló Klebsiella pneumoniae que confirmó el diagnóstico.

Debido a la situación de inestabilidad hemodinámica y el fallo multiorgánico fue necesario el ingreso en UCI con el empleo de aminas. Al séptimo día del ingreso la paciente presentó isquemia con necrosis de los dedos de las manos y de los pies (Figura 1-2). Durante el ingreso fue valorada por el Servicio de Cirugía Vascular y Angiología que indicó amputación de las zonas necrosadas que la paciente rechazó. La evolución clínica fue lentamente favorable hasta la recuperación del cuadro clínico.

El shock séptico se define como un síndrome que se caracteriza por hipotensión arterial en el contexto de sepsis, que persiste a pesar de una adecuada administración de líquidos, lo que da lugar a alteraciones de la perfusión y por tanto se produce disfunción multiorgánica².

Las manifestaciones cutáneas en el contexto de un shock séptico son muy variadas. El mecanismo fisiopatológico que las produce está relacionado con 4 factores principales: coagulación intravascular diseminada (CID), invasión directa de pequeño vaso por los microorganismos, vasculitis inmuno-mediada y embolismos sépticos¹. En la bibliografía actual, se ha conoce que algunas cepas de Klebsiella pneumoniae producen enterotoxinas que actúan lisando las células dando lugar a necrosis de tejidos $3,4,5$. Por lo tanto, las manifestaciones cutáneas en el shock no sólo dependen de la vasculopatía, el estado inmunológico y comorbilidades del paciente, sino que también están relacionadas con microorganismo causante¹.

\section{BIBLIOGRAFÍA}

1. Delgado-Jiménez Y, Fraga J, Requena C, et al. Acute bacterial septic vasculopathy. Int J Dermatol. 2013;52(9):1071-1080.
Figura 1. Necrosis de dedos de la mano derecha

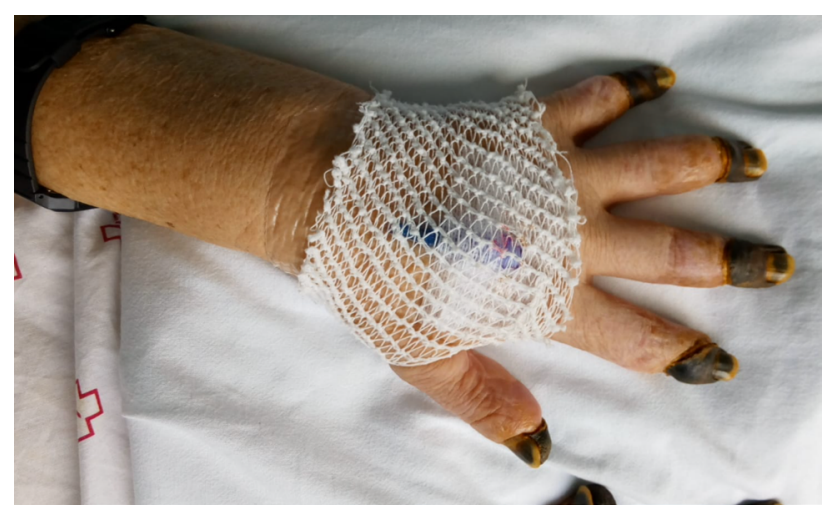

Figura 2. Necrosis de los dedos de los pies

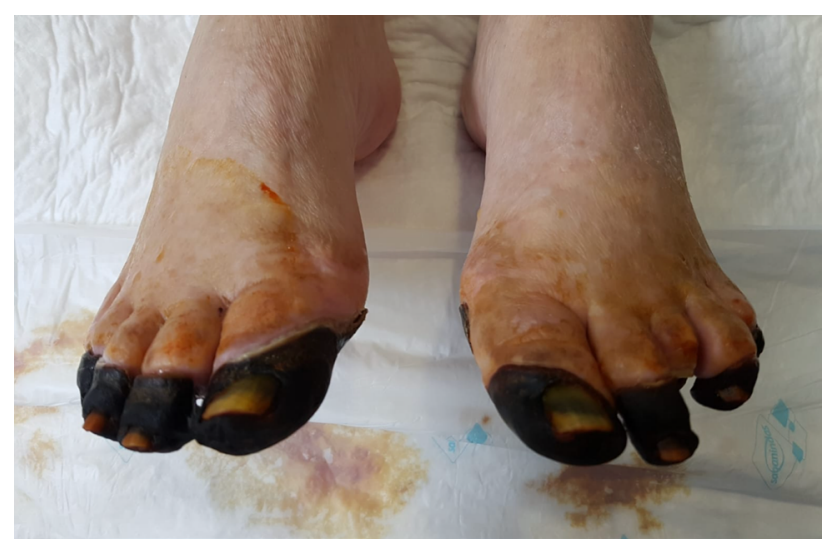

2. Dellinger RP, Levy MM, Rhodes A, et al. Surviving sepsis campaign: international guidelines for management of severe sepsis and septic shock: 2012. Crit Care Med. 2013;41(2):580-637.

3. Tomasini C. Septic vasculitis and vasculopathy in some infectious emergencies: the perspective of the histopathologist. G Ital Dermatol Venereol. 2015;150(1):73-85.

4. Shankar-Sinha S, Valencia GA, Janes BK, et al. The Klebsiella pneumoniae 0 antigen contributes to bacteremia and lethality during murine pneumonia. Infect Immun. 2004;72(3):1423-1430.

5. Cortés G, Borrell N, de Astorza B, Gómez C, Sauleda J, Albertí S. Molecular analysis of the contribution of the capsular polysaccharide and the lipopolysaccharide 0 side chain to the virulence of Klebsiella pneumoniae in a murine model of pneumonia. Infect Immun. 2002;70(5):2583-2590.

Palabras clave: necrosis acral, shock séptico, Klebsiella pneumoniae. Keywords: acral necrosis, septic shock, Klebsiella pneumoniae.

Manuel Francisco Liroa-Romero, Beatriz García-Trincado Unidad de Enfermedades Infecciosas del Hospital Universitario Lucus Augusti

Correspondencia: manlirrom@gmail.com

Cómo citar este artículo: Liroa-Romero MF, García-Trincado B

Necrosis de pies y manos en el shock séptico por Klebsiella pneumoniae. Galicia Clin 2021; 82-1: 54

Recibido: 2/8/2019; Aceptado: 12/8/2019 // https://doi.org/10.22546/60/2054 